\title{
Treatment success of transobturator tape compared with tension free vaginal tape for stress urinary incontinence at 24 months: A randomized controlled trial
}

\author{
Mahmoud Fathy Hassan $^{1 *}$, Osama El-Tohamy ${ }^{1}$, Mostafa Kamel ${ }^{2}$ \\ ${ }^{1}$ Faculty of Medicine, Ain-Shams University, Cairo, Egypt \\ ${ }^{2}$ Faculty of Medicine, Zagazig University, Zagazig, Egypt \\ Email: *mahmoudfathy74@yahoo.com
}

Received 25 January 2014; revised 15 February 2014; accepted 22 February 2014

Copyright (C) 2014 Mahmoud Fathy Hassan et al. This is an open access article distributed under the Creative Commons Attribution License, which permits unrestricted use, distribution, and reproduction in any medium, provided the original work is properly cited. In accordance of the Creative Commons Attribution License all Copyrights (C) 2014 are reserved for SCIRP and the owner of the intellectual property Mahmoud Fathy Hassan et al. All Copyright (C) 2014 are guarded by law and by SCIRP as a guardian.

\section{ABSTRACT}

Objective: To compare the long term efficacy of transobturator Tape (TOT) with tension free vaginal tape (TVT) at 24 months postoperatively. Patients \& Methods: 160 women with stress urinary incontinence (SUI) were randomly allocated to either TVT or TOT procedures and reviewed at $\mathbf{2 4}$ months after surgery. The primary outcomes were objective cure (a negative cough stress test, and a negative 1-hour pad test), and subjective cure (defined as "very much better" or "much better" improvement in the Patient Global Impression of Improvement scale). The secondary outcomes included incontinence related quality of life (using Urogenital Distress Inventory Questionnaire, and Incontinence Impact Questionnaire), and complications. Results: No statistical difference was reported in objective and subjective cure rates between both groups. Objective cure rate was $85.6 \%$ and $81.6 \%$ in the TOT and TVT groups respectively $(P=0.55)$. Subjective cure rate in the TOT and TVT groups were $87 \%$ and $83 \%$ respectively $(P=0.68)$. There were no significant differences in postoperative complications and incontinence related quality of life. However, the operating time was significantly shorter in the TOT group compared with the TVT group (22.6 \pm 3.9 , 27.1 \pm 3 ; respectively, $P<0.001)$. Conclusion: TOT and TVT procedures were equally efficient and safe for treatment of SUI, with maintenance of high objective and subjective cure rates for $\mathbf{2 4}$ months. Longer follow-up is needed to confirm these results.

"Corresponding author.

\section{KEYWORDS}

Urinary Incontinence; Stress; Suburethral Slings; TOT; TVT

\section{INTRODUCTION}

The International Continence Society defines stress urinary incontinence (SUI) as the complaint of involuntary leakage during effort or exertion or during coughing or sneezing [1]. Stress urinary incontinence affects $4 \%$ to $35 \%$ of women, and the prevalence increases with age. Ten percent of middle-aged women report SUI and at least one-third report leakage at least weekly [2].

Stress urinary incontinence can be treated with both non-surgical and surgical treatments. However, conservative treatments for SUI are often of partial or time limited success, and surgery becomes the only solution. More than 200 surgical procedures are described for the treatment of SUI. Minimally invasive synthetic slings have now become the most common procedure performed for SUI [3]. A midurethral sling is now considered the gold standard for SUI treatment with over 103,000 performed annually [4]. Since it was introduced by Ulmsten in 1996, the retropubic tension-free vaginal tape (TVT) procedure has become the surgery of choice for treating SUI [3]. In spite of its proven efficacy, relative safety and widespread adoption, some authors have expressed concern because of reports of rare but serious and, in some cases, life-threatening complications from this procedure. The blind retropubic passage of trocar from the vagina to the abdomen is unique to the TVT and is associated with a $3 \%-9 \%$ bladder perforation rate 
and, on rare occasion, bowel and major vascular damages [5]. In 2001, a surgical technique similar to TVT but that reduced the complication rate by replacing the retropubic route with the transobturator route was proposed. Delorme was the first to describe the transobturator tape (TOT) midurethral sling [6]. The transobturator technique has been advocated because it avoids this retropubic passage and, at least in theory, should reduce the risk of bladder, bowel, and iliac vessel injury [4].

The majority of studies comparing TVT with the TOT had limited follow-up, reported mainly subjective outcomes, and concluded that the transobturator approach is associated with decreased risk of complications, but there is currently no evidence to suggest that one approach results have superior objective or subjective outcomes. The aim of this study was to evaluate the efficacy and safety of TOT compared with TVT in terms of objective and subjective cure rate at 24 months postoperatively.

\section{PATIENTS AND METHODS}

The present study was conducted at the Department of Obstetrics and Gynecology of a large Governmental Military Hospital, Dhahran, Saudi Arabia, from January 2009 till May 2013. The study protocol was approved by the Hospital Research and Ethical Committee, and all patients provided an informed written consent for participation. All the interventions in this trial were conducted in compliance with the Declaration of Helsinki. All methods and definitions conform to the standards proposed by the International Continence Society [1].

Women were eligible for inclusion if they: 1) were visualized leaking urine from the urethra with cough stress test, 2) demonstrated urodynamic SUI on multichannel urodynamic testing, and 3) were suitable for either the TVT or TOT sling procedure. Subjects were excluded if they: 1) demonstrated detrusor over-activity or intrinsic sphincter defect on urodynamic testing, 2) had a post-void residual volume greater than $100 \mathrm{~mL}, 3$ ) had previous incontinence surgery, 4) were requiring concomitant surgery for pelvic organ prolapse, 5) desired future childbearing, 6) had inguinal lymphadenopathy or mass, 7) had a history of a bleeding tendency or were currently on anticoagulation therapy, 8) had a current genitourinary fistula or urethral diverticulum, 9) had Alzheimer's disease, Parkinsonism, or progressive neurological disease as multiple sclerosis, 10) had a contraindication for surgery, or 11) would be unavailable for follow-up.

At baseline, all participants underwent a standardized evaluation, which included urogynecologic history, cough stress test, post-void residual volume and urodynamic evaluation including a filling cystometry, abdominal leak point pressure determination, urethral pressure profile- metry, and uroflowmetry study. All participants were asked to complete the quality of life questionnaire including incontinence-related quality of life questions (Urogenital Distress Inventory [UDI-6], a six-item measure to assess symptoms of urinary incontinence, and Incontinence Impact Questionnaire (IIQ-7), a seven-item measure to assess the impact of urinary incontinence on quality of life [7]).

Women who fulfilled the appropriate criteria were invited to participate in the study. One hundred sixty participants were randomized with equal probability to TVT (control group) or TOT (case group) procedure by computer-generated allocation. The randomization list was generated by the study statistician (using the online research randomizer software

http://www.graphpad.com/quickcalcs/index.cfm) using permuted block randomization with block sizes varying from 4 to 8 . Randomization was stratified by the surgeons. Group allocation was concealed in serially numbered, opaque, and sealed envelopes that were opened in the operating room just before the surgical procedure.

All surgical procedures were executed by one of the surgeons participating in the current study. Anesthesia was either general or spinal, depending on the clinical state and the choice of patients. The TVT procedure was performed using the "bottom up" approach following the technique described by the manufacturer (Gynecare, Ethicon Inc., Somerville, NJ, USA). The TOT procedure wasdone with the Obtryx Halo midurethral sling system (Boston Scientific, Natick, MA, USA) using the technique recommended by the manufacturer. For both procedures the slings were placed "tension-free." All patients underwent intraoperative cystoscopy to assess for lower urinary tract injury. After checking for any injury of urinary bladder, a Foley catheter was inserted, and removed on the first postoperative day.

All participants were invited for follow up in the Urogynecology Clinic at 6 weeks, 6, 12, 18 and 24 months. Outcomes were measured at 24 months after surgery. Data were collected by an independent research nurse. Objective evidence of SUI at 24 months after surgery was obtained by combined negative cough stress test and negative 1-hour pad test (if the pad weight gain was less than $1 \mathrm{~g}$ after the one hour test period).Women undertaking the pad test had retrograde bladder filling with $300 \mathrm{~mL}$ of sterile water and wore pre-weighed pads while they undertook the physical activities recommended by the International Continence Society [8]. Perioperative complications were identified from the hospital and follow-up charts. At the 24-month follow-up, women undertook a urine-flow test to assess voiding dysfunction. Subjective symptom assessment by questionnaire took place 24 months after surgery. Patient global improvement in the bladder function was assessed by the Patient 
Global Impression of Improvement scale (PGI-I) [9]. It is a scale of seven items to describe how is the bladder condition after the treatment, compared to how it was before treatment. Subjective cure was defined as "very much better" or "much better" by the PGI-I scale. Additionally, all women were asked at 24 months to complete IIQ-7 and UDI-6 questionnaire [9]. Each measure produces a single score of 0 (no impact for IIQ-7, no distress for UDI-6) to 21 for IIQ-7 (maximum impact) and 18 for UDI-6 (maximum distress).

The required sample size was estimated by a priori analysis using the G*power3 program (Heinrich-HeineUniversität, Düsseldorf, Germany). Sample size calculations assumed an $80 \%$ success in the TVT group [10]. To detect a difference of approximately $20 \%$ between the two groups, assuming $80 \%$ power and a two-sided significance level of 0.05 , a sample of 70 patients per group with complete follow-up would be required (total 140). Anticipating a $10 \%$ loss to follow-up and/or dropout rate over the period of the study, the total enrollment goal was 160 .

Analyses were undertaken following the intention to treat principle: women were analyzed in the surgical group to which they were randomized. A single analysis was planned when all women had completed the 24 months follow-up. The Kolgomorov-Smirnov test was applied to check the deviation from Gaussian distribution. The median (range), mean (standard deviation), or number (\%) was used to present the data according to distribution. Unpaired student $t$ test was used for normally distributed continuous variables, while the non-normally distributed variables were compared by the Mann-Whitney $U$ test. The Fisher exact test was used for analysis of categorical variables. Two tailed $P$ value $<0.05$ was considered statistically significant. Statistical analysis was accomplished by using the Statistical Package for Social Sciences, version 14.0 (SPSS Inc., Chicago, IL, USA).

\section{RESULTS}

The study recruited 238 women between January 2009 and May 2013. Figure 1 shows the patients flowchart. Seventy eight women withdrew before randomization and were not included in the analysis. One hundred sixty participants were randomized and allocated to surgery. One hundred fifty-three patients (95.6\%) completed 24 months of follow-up. Baseline data were presented in Table 1. Mean age was 53.1 years for the TVT group and 51.6 for the TOT group. The median parity of both groups was 5 . No statistical difference between the two groups was found in the BMI, the menopausal status, and the preoperative urodynamic parameters. Median IIQ-7 scores were 8 for the TVT group and 9 for the TOT group. Meanwhile, median UDI-6 scores were 8 for both

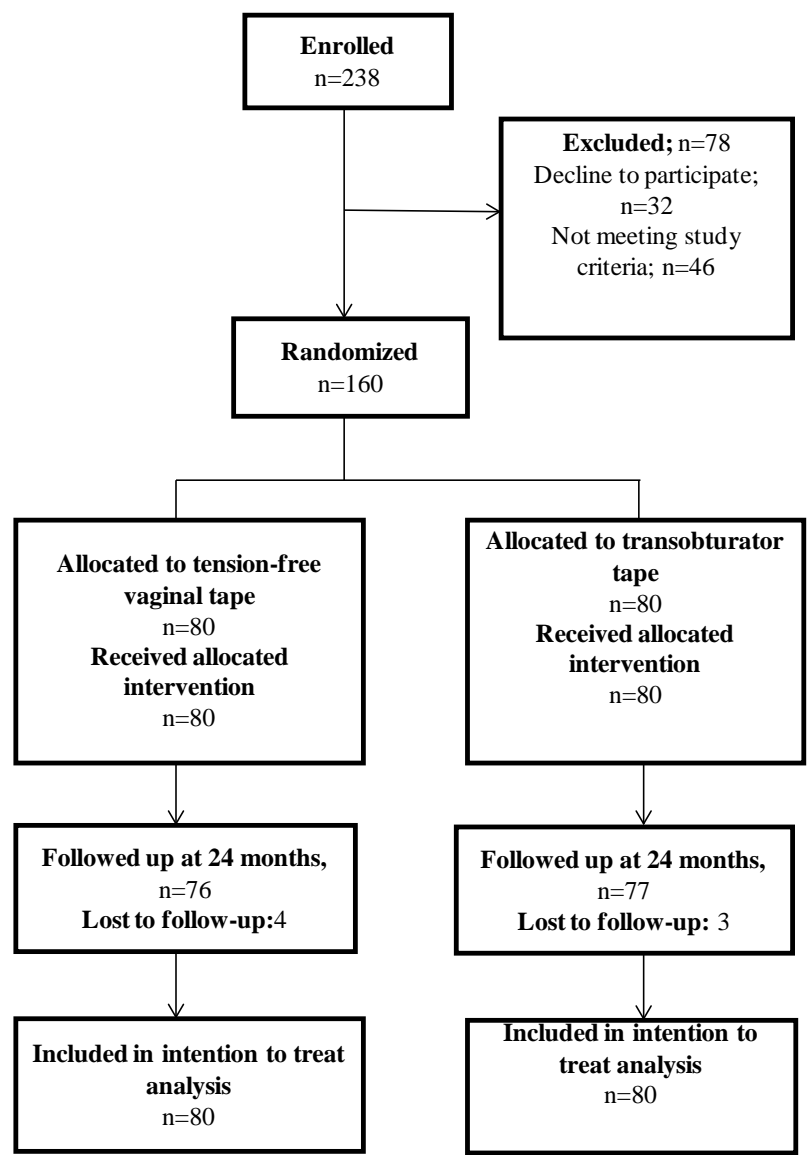

Figure 1. Flow chart of patient recruitment, follow-up and analysis.

groups with no statistical difference between both groups in both questionnaires.

Hospital data and intraoperative and postoperative complications were presented in Table 2. Operating time was significantly longer in the TVT group compared with the TOT group $(27.1 \pm 3,22.6 \pm 3.9$; respectively, $P$ $<0.001)$. Estimated blood loss, change in hematocrit, and length of hospital stay were similar between the two groups. There was no major perioperative complication. There were 3 bladder perforations in the TVT group and none in the TOT group. Meanwhile, there was one case of vaginal wall perforation in the TOT group and none in the TOT group. During long-term follow-up, recurrent urinary tract infection occurred in 10 (12.5\%) patients in the TVT group and $7(8.8 \%)$ patients in the TOT group $(P$ $=0.61)$. Mesh erosion developed in one patient in the TOT group and was cured after 5 months by removing the part of the mesh ejected out and suturing the above mucosa. On the contrary, no case with mesh erosion was reported in the TVT group. Furthermore, No leg or obturator complications developed in either group during the perioperative period. Voiding dysfunction was not statistically different between the two study groups $(P=0.1)$. 
Table 1. Clinical, demographic, and preoperative characteristics.

\begin{tabular}{|c|c|c|c|}
\hline Variable & TVT $\mathbf{N}=80$ & TOT $\mathbf{N}=\mathbf{8 0}$ & $P$-value \\
\hline Age & $53.1 \pm 8.1$ & $51.6 \pm 7.9$ & $0.24^{*}$ \\
\hline BMI & $29.9 \pm 5.5$ & $30.4 \pm 4.9$ & $0.56^{*}$ \\
\hline Parity & $5(2-8)$ & $5(2-9)$ & $0.37^{\dagger}$ \\
\hline \multicolumn{4}{|l|}{ Menopausal status } \\
\hline Premenopausal & $43(53.8 \%)$ & $48(60 \%)$ & $0.52^{\ddagger}$ \\
\hline Postmenopausal with HRT & $24(30 \%)$ & $21(26.3 \%)$ & $0.73^{\ddagger}$ \\
\hline Postmenopausal without HRT & $13(16.2 \%)$ & $11(13.7 \%)$ & $0.83^{\ddagger}$ \\
\hline IIQ-7 & $8(0-21)$ & $9(0-21)$ & $0.76^{\dagger}$ \\
\hline UDI-6 & $8(0-18)$ & $8(0-18)$ & $0.79^{\dagger}$ \\
\hline \multicolumn{4}{|l|}{ Preoperative urodynamic parameters: } \\
\hline Maximum urine flow rate $(\mathrm{mL} / \mathrm{s})$ & $29 \pm 3.7$ & $29.9 \pm 4.5$ & $0.18^{*}$ \\
\hline MUCP $\left(\mathrm{cm} \mathrm{H}_{2} \mathrm{O}\right)$ & $50.9 \pm 8.2$ & $52.6 \pm 6.8$ & $0.17^{*}$ \\
\hline VLPP $\left(\mathrm{cm} \mathrm{H}_{2} \mathrm{O}\right)$ & $94.1 \pm 4.6$ & $93.3 \pm 3.9$ & $0.2^{*}$ \\
\hline $\operatorname{PVR}(\mathrm{mL})$ & $28.2 \pm 4.7$ & $29.1 \pm 5.8$ & $0.26^{*}$ \\
\hline
\end{tabular}

TVT, tension-free vaginal tape; TOT, transobturator tape; BMI, body mass index; HRT; hormone replacement therapy; IIQ-7, Incontinence Impact Questionnaire; UDI-6, Urogenital Distress Inventory Questionnaire; MUCP, maximal urethral closure pressure; VLPP, valsalva leak point pressure; PVR, post-voiding residual. Data are mean (standard deviation), median (range), or number (\%). ${ }^{*}$ Student $t$ test was used, ${ }^{\dagger}$ Mann-Whitney $U$ test was used, ${ }^{\ddagger}$ Fisher exact test was used. $P$ value $<0.05$ is significant.

Table 2. Hospital data and intraoperative and postoperative complications.

\begin{tabular}{|c|c|c|c|}
\hline Variable & TVT $\mathbf{N}=80$ & TOT $\mathbf{N}=80$ & $P$-value \\
\hline Operating time (min) & $27.1 \pm 3$ & $22.6 \pm 3.9$ & $<0.001^{*}$ \\
\hline Estimated blood loss (mL) & $45(25-350)$ & $35(20-300)$ & $0.09^{\dagger}$ \\
\hline Change in hematocrit (\%) & $5(2-9)$ & $5(2-8)$ & $0.07^{\dagger}$ \\
\hline Hospital stay (d) & $1.4 \pm 0.6$ & $1.2 \pm 0.5$ & $0.19^{*}$ \\
\hline $\begin{array}{c}\text { Intraoperative complications } \\
\text { Bladder injury } \\
\text { Vaginal wall perforation } \\
\text { Urethral injury } \\
\text { Postoperative complications }\end{array}$ & $\begin{array}{c}3(3.8 \%) \\
0 \\
0\end{array}$ & $\begin{array}{c}0 \\
1(1.3 \%) \\
0\end{array}$ & $\begin{array}{c}0.25^{\ddagger} \\
1^{\ddagger}\end{array}$ \\
\hline $\begin{array}{l}\text { Postoperative complications } \\
\text { Urinary tract infections } \\
\text { Leg/obturator complication } \\
\text { Voiding dysfunction } \\
\text { Mesh erosion }\end{array}$ & $\begin{array}{c}10(12.5 \%) \\
0 \\
8(10 \%) \\
0\end{array}$ & $\begin{array}{l}7(8.8 \%) \\
0 \\
2(2.5 \%) \\
1(1.3 \%)\end{array}$ & $\begin{array}{c}0.61^{\ddagger} \\
1^{\ddagger} \\
0.1^{\ddagger} \\
1^{\ddagger}\end{array}$ \\
\hline
\end{tabular}

TVT, tension-free vaginal tape; TOT, transobturator tape. Data are mean (standard deviation), median (range), or number (\%). ${ }^{*}$ Student $t$ test was used, ${ }^{\dagger}$ MannWhitney $U$ test was used, ${ }^{\ddagger}$ Fisher exact test was used. $P$ value $<0.05$ is significant.

In the TVT group, four subjects (5\%) required a sling release, and an additional four subjects (5\%) required prolonged urinary catheterization (4 - 6 weeks) postoperatively. In contrast, only two subjects in the TOT group (2.5\%) required prolonged catheterization.

Statistical analysis failed to detect any significant differences between TVT and TOT procedure with regard to objective and subjective cure rates (Table 3). Sixty two (81.6\%) and 66 (85.6\%) women were objectively cured in the TVT and the TOT groups, respectively $(P=$ $0.55)$. Subjective cure rate was assessed by the Patient Global Impression of Improvement (GPI-I) scale which revealed that 63 (83\%) and 67 (87\%) women expressed to be very much better or much better in the patient GPI-I scale in the TVT and the TOT groups, respectively $(P=0.68)$. Quality of life was statistically equivalent for both groups as reported using IIQ-7 and UDI-6 questionnaire (Table 3). On the other hand, Table 3 displayed no statistically significant difference between the
TVT and TOT procedures for postoperative urodynamic parameters concerning bladder outlet obstruction (Maximum urine flow rate, and post-voiding residual).

\section{DISCUSSION}

The National Institute of Health (NIH) has emphasized the importance of evaluating efficacy of SUI therapies with composite outcomes that include subjective and objective efficacy measures. [11] In this study, we prospectively compared the effectiveness of TVT and TOT in treating SUI using validated objective and subjective measures at 24 months postoperatively. Our trial showed that there was statistical and clinical equivalence in the rates of treatment success according to objective and subjective criteria between the two performed midurethral sling procedures for the treatment of SUI in women. Patient-reported satisfaction with the results of the procedure, and improvement in quality of life were also sim- 
Table 3. Objective and subjective cure rates after 24 months.

\begin{tabular}{|c|c|c|c|}
\hline Variable & TVT N $=76$ & TOT $N=77$ & $P$-value \\
\hline Negative cough stress test $\&$ negative 1 -hour pad test & 62 (81.6) & 66 (85.6) & $0.55^{\dagger}$ \\
\hline $\begin{array}{c}\text { Urodynamic parameters } \\
\text { Maximum urine flow rate }(\mathrm{mL} / \mathrm{s}) \\
\text { PVR }(\mathrm{mL})\end{array}$ & $\begin{array}{c}27.5 \pm 5.5 \\
36.4 \pm 14.2\end{array}$ & $\begin{array}{c}27.8 \pm 4 \\
32.7 \pm 11.2\end{array}$ & $\begin{array}{l}0.74^{\ddagger} \\
0.08^{\ddagger}\end{array}$ \\
\hline IIQ-7 & $0(0-21)$ & $0(0-20)$ & $0.67^{\S}$ \\
\hline UDI-6 & $0(0-18)$ & $0(0-18)$ & $0.63^{\S}$ \\
\hline $\begin{array}{c}\text { PGI-I } \\
\text { Very Much Better } \\
\text { Much Better } \\
\text { A Little Better } \\
\text { No Change } \\
\text { A Little Worse } \\
\text { Much Worse } \\
\text { Very Much Worse }\end{array}$ & $\begin{array}{l}44(58 \%) \\
19(25 \%) \\
3(3.9 \%) \\
4(5.3 \%) \\
3(3.9 \%) \\
2(2.6 \%) \\
1(1.3 \%)\end{array}$ & $\begin{array}{c}46(59.7 \%) \\
21(27.3 \%) \\
4(5.2 \%) \\
3(3.9 \%) \\
2(2.6 \%) \\
1(1.3 \%) \\
0\end{array}$ & $\begin{array}{c}0.87^{\dagger} \\
0.86^{\dagger} \\
1^{\dagger} \\
1^{\dagger} \\
1^{\dagger} \\
1^{\dagger} \\
1^{\dagger}\end{array}$ \\
\hline Subjective cure rate $^{*}$ & $63(83 \%)$ & $67(87 \%)$ & $0.68^{\dagger}$ \\
\hline
\end{tabular}

TVT, tension-free vaginal tape; TOT, transobturator tape; PVR, post-voiding residual; IIQ-7, Incontinence Impact Questionnaire; UDI-6, Urogenital Distress Inventory Questionnaire; PGI-I, Patient Global Impression of Improvement. *Subjective cure rate: defined as "very much better” or "much better" by the Patient Global Impression of Improvement scale. Data are mean (standard deviation), median (range), or number (\%). ${ }^{\dagger}$ Fisher exact test was used, ${ }^{\ddagger}$ Student $t$ test was used, ${ }^{\S}$ Mann-Whitney $U$ test was used. $P$ value $<0.05$ is significant.

ilar between the two procedures. However, TOT showed a significantly shorter operating time.

Many systematic reviews have evaluated the efficacy of TOT compared with TVT, without finding clear differences in the objective and subjective cure rates [1215]. Objective cure after TOT ranged from $84 \%$ to $98 \%$; and for TVT it ranged from $86 \%$ to $99 \%$. The wide range in objective cure rates caused by the use of different methods for the assessment of objective cure rate as urodynamic assessment, negative cough-stress test, $1 \mathrm{~h}$ pad test of $2 \mathrm{~g}$ or less, $1 \mathrm{~h}$ pad test of $1 \mathrm{~g}$ or less, or $24 \mathrm{~h}$ pad test of $5 \mathrm{~g}$ or less. Similarly, Freedman et al. [16] evaluated both approaches at 12 months, and revealed $65.5 \%$ of the TVT group and $63.4 \%$ of the TOT group reported no SUI. In addition, there was a similar improvement in patient satisfaction, quality of life, and sexual function between the TOT and TVT groups. Likewise, a study by Wadie and El-Hefnawy [17] stated that both tapes had similar objective and subjective cure rates of incontinence at two years follow up.

On the contrary, Albo and colleagues [18] evaluated the treatment success of TVT and TOT at 24 Months, and conveyed higher objective and subjective cure rates in the TVT group. The objective success rate for the retropubic and transobturator sling was $77.3 \%$ and $72.3 \%$, respectively (95\% CI for difference of $5.1 \%$ was $-2.0 \%$, $12.1 \%$, while the subjective success rate was $55.7 \%$ and $48.3 \%$, respectively (95\% CI for difference of $7.4 \%$ was $-0.7 \%, 15.5 \%)$. However, neither the objective nor the subjective success rates met the pre-specified criteria for equivalence. Moreover, each of the confidence intervals included $0 \%$, indicating that the success rates also cannot be considered different from one another.

The present study displayed that duration of operation was significantly shorter with TOT procedure, with a mean duration of $22.6 \pm 3.9$ min compared to $27.1 \pm 3$ min for the TVT $(P<0.001)$. Similarly, a systematic review by Ogah et al. [14] stated that a significantly shorter mean operation time was reported with TOT compared with TVT (20 min, $27 \mathrm{~min}$; respectively), with mean difference $5.5 \mathrm{~min}$ (95\% CI 5.0 - 6.0). On the other hand, our data revealed that three patients (4\%) had bladder perforation in the TVT group, but with no statistical significance when compared to TOT $(P=0.25)$. Bladder perforation was found to be the most commonly reported complication for TVT in studies comparing TVT with TOT $[5,14,19]$. In addition, our data revealed that TVT had a non-statistically significant higher incidence of UTI and voiding dysfunction (assessed by urine flow test at 24 months). Our findings are consistent with previous reports of higher rates of voiding dysfunction after TVT procedure than after TOT procedure $[18,20]$. The higher rate of this complication in the TVT group may be due to the relatively greater urethral obstruction that results from the fact that the anatomic relationship between the sling and the urethra is different for the TOT than for retropubic slings. In the TVT, the sling axis is roughly vertical in relation to the urethral axis, whereas the axis of the TOT is more horizontal. As such, TOT provides less circumferential compression of the urethra than does the TVT. This decreased compression may result in fewer postoperative voiding difficulties and irritating bladder symptoms [5].

This study had several strengths. The study was prospective and randomized design. Objective and subjective measures of surgical success were used to capture a broad spectrum of outcomes. Rates of participant assessment two years after surgery were high. Our study did not in- 
clude patients requiring concomitant procedures such as hysterectomy or prolapse repair, allowing us to be confident that the outcomes measured were related to the SUI surgery. However, our study had some limitations included a non-blinded study design of surgeon and patient to the treatment assignment. The study power was not enough to validate the comparison of safety profile between both procedures. So, it is important to have larger multicenter prospective studies within ethnically different populations to reach a more powerful conclusion and to evaluate the relative risk of the adverse events that have been seen with both procedures. As well, studies with longer follow-up are necessary to determine if the efficacy of TOT is durable.

\section{CONCLUSION}

In conclusion, no significant differences in objective and subjective outcomes between women who had TOT or TVT procedures at 24 months follow up. Both procedures had similar complication rate. However, TOT procedure had a shorter operating time.

\section{ACKNOWLEDGEMENTS}

No financial or commercial interests from any company were involved.

\section{CONFLICT OF INTEREST}

No conflict of interest is declared by authors.

\section{REFERENCES}

[1] Abrams, P., Cardoze, L., Fall, M., Griffiths, D., Rosier, P., Ulmsten, U., et al. (2003) The standardization of terminology of lower urinary tract function: Report from the Standardization Subcommittee of the International Continence Society. Urology, 61, 37-49. http://dx.doi.org/10.1016/S0090-4295(02)02243-4

[2] Hota, L.S., Hanaway, K., Hacker, M.R., Disciullo, A., Elkadry, E., Dramitinos, P., et al. (2012) TVT-secur (hammock) versus TVT-obturator: A randomized trial of suburethral sling operative procedures. Female Pelvic Medicine and Reconstructive Surgery, 18, 41-45. http://dx.doi.org/10.1097/SPV.0b013e31823bdbcf

[3] Schierlitz, L., Dwyer, P.L., Rosamilia, A., Murray, C., Thomas, E., De Souza, A., et al. (2012) Three-year follow-up of tension-free vaginal tape compared with transobturator tape in women with stress urinary incontinence and intrinsic sphincter deficiency. Obstetrics and Gynecology, 119, 321-327. http://dx.doi.org/10.1097/AOG.0b013e31823dfc73

[4] Parden, A.M., Gleason, J.L., Jauk, V., Garner, R., Ballard, A. and Richter, H.E. (2013) Incontinence outcomes in women undergoing primary and repeat midurethral sling procedures. Obstetrics and Gynecology, 121, 273-278.

[5] Barber, M.D., Kleeman, S., Karram, M.M., Paraiso, M.F.,
Walters, M.D., Vasavada, S., et al. (2008) Transobturator tape compared with tension-free vaginal tape for the treatment of stress urinary incontinence: A randomized controlled trial. Obstetrics and Gynecology, 111, 611-621. http://dx.doi.org/10.1097/AOG.0b013e318162f22e

[6] Han, J.Y., Choo, M.S., Lee, Y.S., Seo, J.T., Kim, J.H., Kim, Y.H., et al. (2013) Effectiveness of retropubic tension-free vaginal tape and transobturator inside-out tape procedures in women with overactive bladder and stress urinary incontinence. International Neurourology Journal, 17, 145-151. http://dx.doi.org/10.5213/inj.2013.17.3.145

[7] Uebersax, J.S., Wyman, J.F., Shumaker, S.A., McClish, D.K. and Fantl, J.A. (1995) Short forms to assess life quality and symptom distress for urinary incontinence in women: The Incontinence Impact Questionnaire and the Urogenital Distress Inventory. Continence Program for Women Research Group. Neurourology and Urodynamics, 14, 131-139.

http://dx.doi.org/10.1002/nau.1930140206

[8] Ward, K.L., Hilton, P., UK and Ireland TVT Trial Group (2004) A prospective multicenter randomized trial of tension-free vaginal tape and colposuspension for primary urodynamic stress incontinence: Two-year follow-up. American Journal of Obstetrics \& Gynecology, 190, 324331. http://dx.doi.org/10.1016/j.ajog.2003.07.029

[9] Yalcin, I. and Bump, R.C. (2003) Validation of two global impression questionnaires for incontinence. American Journal of Obstetrics \& Gynecology, 189, 98-101. http://dx.doi.org/10.1067/mob.2003.379

[10] Ross, S., Robert, M., Swaby, C., Dederer, L., Lier, D., Tang, S., et al. (2009) Transobturator tape compared with tension-free vaginal tape for stress incontinence: A randomized controlled trial. Obstetrics and Gynecology, 114, 1287-1294.

http://dx.doi.org/10.1097/AOG.0b013e3181c2a151

[11] Weber, A.M., Abrams, P., Brubaker, L., Cundiff, G., Davis, G., Dmochowski, R.R., et al. (2001) The standardization of terminology for researchers in female pelvic floor disorders. International Urogynecology Journal and Pelvic Floor Dysfunction, 12, 178-186. http://dx.doi.org/10.1007/PL00004033

[12] Novara, G., Artibani, W., Barber, M.D., Chapple, C.R., Costantini, E., Ficarra, V., et al. (2010) Updated systematic review and metaanalysis of the comparative data on colposuspension, pubovaginal slings, and midurethral tapes in the surgical treatment of female stress urinary incontinence. European Urology, 58, 218-238. http://dx.doi.org/10.1016/j.eururo.2010.04.022

[13] Latthe, P.M., Singh, P., Foon, R. and Toozs-Hobson, P. (2010) Two routes of transobturator tape procedures in stress urinary incontinence: A meta-analysis with direct and indirect comparison of randomized trials. BJU International, 106, 68-76.

http://dx.doi.org/10.1111/j.1464-410X.2009.09051.x

[14] Ogah, J., Cody, J.D. and Rogerson, L. (2011) Minimally invasive synthetic suburethral sling operations for stress urinary incontinence in women. Neurourology and Urodynamics, 30, 284-291. http://dx.doi.org/10.1002/nau.20980

[15] Barboglio, P.G. and Gormley, E.A. (2013) Retropubic 
versus transobturator slings-Are the outcomes changing with time? Current Urology Reports, 14, 386-394. http://dx.doi.org/10.1007/s11934-013-0337-6

[16] Freeman, R., Holmes, D., Hillard, T., Smith, P., James, M., Sultan, A., et al. (2011) What patients think: Patientreported outcomes of retropubic versus trans-obturator mid-urethral slings for urodynamic stress incontinence: A multicentrerandomised controlled trial. International Urogynecology Journal, 22, 279-286. http://dx.doi.org/10.1007/s00192-010-1343-6

[17] Wadie, B.S. and El-Hefnawy, A.S. (2013) TVT versus TOT, 2-year prospective randomized study. World Journal of Urology, 31, 645-649.

http://dx.doi.org/10.1007/s00345-012-0956-4

[18] Albo, M.E., Litman, H.J., Richter, H.E., Lemack, G.E.,
Sirlsm L.T., Chai, T.C., et al. (2012) Treatment success of retropubic and transobturator mid urethral slings at 24 months. Journal of Urology, 188, 2281-2287. http://dx.doi.org/10.1016/j.juro.2012.07.103

[19] Sirls, L.T., Tennstedt, S., Lukacz, E., Rickey, L., Kraus, S.R., Markland, A.D., et al. (2012) Condition-specific quality of life 24 months after retropubic and transobturator sling surgery for stress urinary incontinence. Female Pelvic Medicine \& Reconstructive Surgery, 18, 291-295. http://dx.doi.org/10.1097/SPV.0b013e318267c004

[20] Richter, H.E., Albo, M.E., Zyczynski, H.M., Kenton, K., Norton, P.A., Sirls, L.T., et al. (2010) Retropubic versus transobturatormidurethral slings for stress incontinence. New England Journal of Medicine, 362, 2066-2076. http://dx.doi.org/10.1056/NEJMoa0912658

PGI-I: Patient global impression of improvement scale;

PVR: Post-voiding residual;

SUI: Stress urinary incontinence;

TOT: Transobturator tape;

TVT: Tension-free vaginal tape;

UDI-6: Urogenital distress inventory questionnaire;

VLPP: Valsalva leak point pressure. 